\title{
Electrochemical Determination of Carbendazim in Water Base on Carbon Dots Modified Glassy Carbon Electrode
}

\author{
Linyan Bian ${ }^{1}$, Chunli Li ${ }^{1}$ and Haitao Zong, ${ }^{2, *}$ \\ ${ }^{1}$ School of Chemistry and Chemical Engineering, Henan Polytechnic University, Jiaozuo 454000, \\ China \\ ${ }^{2}$ School of Physics and Electronic Information Engineering, Henan Polytechnic University, \\ Jiaozuo 454000, China \\ *E-mail: haitaozong@163.com
}

doi: $10.20964 / 2017.05 .55$

Received: 30 October 2016 / Accepted: 11 February 2017 / Published: 12 April 2017

Through the urea and sodium citrate electrochemical carbonizing, one-pot method which is convenient and economical, is employed to fabricate the water soluble carbon dots (designated as C-Dots). By developing electrochemical sensor with high sensitivity, where the glassy carbon electrode was decorated by C-Dots, the carbendazim was then determined by different pulse voltammetry. The $\left[\mathrm{Fe}(\mathrm{CN})_{6}\right]^{3-14-}$ was used as an electrochemical probe to investigate the electrochemical specific property of the decorated electrode. The electron transfer on larger surface of electrode demonstrated faster rate in C-Dots/GCE than that on electrode with any functionalization. On the decorated electrode, the cycle voltammetry was employed to investigate the electrochemical carbendazim actions. The excellent performance in electrochemically oxidizing carbendazim is exhibited by CDots/GCE. With optimized condition, excellent linearity was observed in the well-established sensor of C-Dots/GCE by combining the peak current and carbendazim concentration, where the $10 \mathrm{nM}$ was considered to be the limitation with the range $(0.1-10 \mu \mathrm{M})$. The carbendazim can be successfully and effectively determined in the water sample by using this proposed sensor.

Keywords: Carbon dots; Electrochemical sensor; Oxidation; One-pot; Electroanalysis

\section{$\underline{\text { FULL TEXT }}$}

(C) 2017 The Authors. Published by ESG (www.electrochemsci.org). This article is an open access article distributed under the terms and conditions of the Creative Commons Attribution license (http://creativecommons.org/licenses/by/4.0/). 